\title{
Effect of Some Performance Indicators of Mathematics in the Nalerigu Senior High School
}

\author{
Hussein Salifu \\ Department of Statistics, Faculty of Mathematical Sciences, \\ University for Development Studies, Navrongo, Ghana. \\ Gabriel Nyamekye \\ Department of Statistics, School of Applied Sciences, \\ Tamale Technical University, Tamale, Ghana. \\ Adam Issahaku \\ Department of Statistics, Faculty of Mathematical Sciences, \\ University for Development Studies, Navrongo, Ghana.
}

doi: 10.19044/esj.2016.v13n3p429 URL:http://dx.doi.org/10.19044/esj.2016.v13n3p429

\begin{abstract}
This study employed the multivariate analysis of variance (MANOVA) procedure to examine the influence of students' sex, age and course of study (department) on mathematics performance in Nalerigu Senior High School of the East Mampurisi district in the Northern of Ghana. The results showed that male students perform better on the average for all the mathematics performance indicators (understanding, knowledge and perception). The MANOVA analysis revealed that students performance in mathematics do not differ across sex (gender) and age group. The results however showed that there was significant difference in performance of mathematics across course of study (department). However, the univariate analysis of variance (ANOVA) results revealed that there was no sex difference in understanding and knowledge of mathematics while significant differences exist in perception of mathematics among male and female students. Further, the study revealed a significant difference in students understanding and knowledge in mathematics and no bias in perception of mathematics among students age. The study therefore recommended that, the Ministry of Education, school managements and other stakeholders such as Non Governmental Organizations should sensitize students to discard beliefs and practices that prohibit effective participation of female students which result to poor performance in mathematics.
\end{abstract}

Keywords: Understanding, Knowledge, Perception, Box's $\mathrm{M}$ test, MANOVA 


\section{Introduction}

Mathematics is the foundation of scientific and technological knowledge that is vital in socio-economic development of every country. Because of this Mathematics is a compulsory subject at both primary and senior levels in Ghana. Mathematics is also used as a basic entry requirement into any of the prestigious courses such as medicine, architecture and engineering among other degree programmes (Ministry of Education, 1986). Many attempts have been made to improve students understanding of mathematics, knowledge in mathematics as well as good perception of mathematics has not resulted in greater achievement in mathematics of Senior High Schools. Students in second year of study still struggle with mathematical concepts and skills. Many students discontinued higher level mathematics studies because of failure in mathematics as a result of poor understanding, poor knowledge and wrong perception about mathematics (Egodawatte, 2011). Thus, it can be argued that a better understanding in mathematics, knowledge in mathematics and perception of mathematics would helps improves the performance of mathematics. Given the important role Mathematics plays in society, there has been a gender disparity in mathematics ability and achievement. This has remained a great source of concern as many researches' attempts to change the dwindling trend of women at the highest levels of mathematics.

Considerable literature exists in reporting attempts to explain gender differences in mathematics performance. Ajai and Imoko., (2015) employed the t-test to assessed gender differences in mathematics achievement and retention by using Problem-Based Learning (PBL) in Nigeria. The study established that male and female students taught algebra using PBL did not significantly differ in achievement and retention scores, thereby revealing that male and female students are capable of competing and collaborating in mathematics.

O’Connor-Petruso et al., (2004) have shown that gender differences in mathematics achievement become apparent at the secondary level when female students begin to exhibit less confidence in their mathematics ability and perform lower than males on problem solving and higher level mathematics tasks.

Zachariah et al., (2012) in Kenya reported that Students' personal factors contributing to poor performance in Mathematics were gender, economic factors and attitude towards mathematics. Students' attitude towards mathematics was measured using likert scale and the results obtained indicated that they have a positive attitude towards mathematics.

This study therefore seeks to examine whether there is significant difference in students understanding, knowledge and perception in mathematics across sex, age and department of study 


\section{Method and Materials}

The study was conducted in the East Mamprusi District in the northern region of Ghana. It has Gambaga as its capital town. According to the 2010 population and housing census (PHC, 2010) East Mamprusi District has a total population of 121,009 representing 4.9 percent of the total population in Ghana, males constitute 49 percent and females representing 51 percent. However, a higher population of males (25.5\%) compared to females 18.3 percent attended Senior High School. The district has two Senior High Schools, Nalerigu senior high and Gambaga Girls Senior High School, but the study was conducted at Nalerigu senior high school. Nelerigu senior high has a total student population of 489 comprising of 91 General Science, 333 Arts students and 65 Business students. The school has a male dominated student's population of 322 over females of 167 .

Data for this study was collected based on a problem based test answered by students (respondents) at Nalerigu senior high school. The test consisted of five questions each on the performance indicators of mathematics (understanding, knowledge and perceptions of mathematics) and each set of questions marked over ten. Second year students of Nalerigu senior high school was the target population. A proportionate stratified random sample size of 30 males and females student were used. Students' age was categorized into three different categories comprising; less than 15 years, $15-20$ years and $21-25$ years and coded as categories. The coding of the independent variables were as follows: Age: 1= less than 15 years, 2 $=15-20$ years, $3=21-25$ years; Sex: $1=$ Male, $2=$ Female. Departments: $1=$ Science $2=$ Arts, $3=$ Business.

\subsection{Multivariate Analysis of Variance (MANOVA)}

MANOVA involves analysis of several population means. This technique provides a multivariate test to compare the mean vectors of $\mathrm{k}$ random samples for significant differences when the levels of the grouping variables are two or more. The technique assumes samples are independent, the populations have a common covariance matrix and each population is multivariate normal distribution. The assumptions mentioned serve as guide for using MANOVA for analysis.

Consider $\mathrm{k}$ independent random samples of size $\mathrm{n}$ obtained from $p-$ variate normal populations. The model for each observation is;

$$
X_{i j}=\mu+\tau_{i}+\varepsilon_{i j}, j=1,2, \cdots, n_{i} \text { and } i=1,2, \cdots, g
$$

Where $\varepsilon_{i j}$ are independent $N_{p}(0, \Sigma)$ variables whiles the vector $\mu$ is an overall mean and $\tau_{i}$ represent the ith treatment effect with $\sum_{i=1}^{g} n_{i} \tau_{i}=0$. 
The components of $X_{i j}$ is a sample of $N_{p}\left(\mu_{i}, \Sigma\right)$ population and that the random samples are independent. Each observation vector $X_{i j}$ in model (1) can be decomposed into components of treatments and residuals effects as;

$$
x_{i j}=\bar{x}+\left(\bar{x}_{i}-\bar{x}\right)+\left(x_{i j}-\bar{x}_{i j}\right)
$$

(2)

The decomposition can further be transformed into multivariate sums of squares and cross-products by considering;

$$
\begin{aligned}
\left(x_{i j}-\bar{x}\right)\left(x_{i j}-\bar{x}\right)^{\prime}= & {\left[\left(x_{i j}-\bar{x}_{i}\right)+\left(\bar{x}_{i}-\bar{x}\right)\right]\left[\left(x_{i j}-\bar{x}_{i}\right)+\left(\bar{x}_{i}-\bar{x}\right)\right] } \\
=\left(x_{i j}-\bar{x}_{i}\right)\left(x_{i j}-\bar{x}_{i}\right)^{\prime} & +\left(x_{i j}-\bar{x}_{i}\right)\left(\bar{x}_{i}-\bar{x}\right)^{\prime}+\left(\bar{x}_{i}-\bar{x}\right)\left(x_{i j}-\bar{x}_{i}\right)^{\prime} \\
& +\left(\bar{x}_{i}-\bar{x}\right)\left(\bar{x}_{i}-\bar{x}\right)^{\prime}
\end{aligned}
$$

After summing the middle two expressions over $j$ and the cross product over $i$ and $j$, the expression becomes;

$$
\sum_{i=1}^{g} \sum_{j=1}^{n_{i}}\left(x_{i j}-\bar{x}\right)\left(x_{i j}-\bar{x}\right)^{\prime}=\sum n_{i}\left(\bar{x}_{i}-\bar{x}\right)\left(\bar{x}_{i}-\bar{x}\right)^{\prime}+\sum_{i=1}^{g} \sum_{j=1}^{n_{i}}\left(x_{i j}-\bar{x}_{i}\right)\left(x_{i j}-\bar{x}_{i}\right)^{\prime}
$$

(Johnson \& Wichern, 2007)

We wish to compared the means of $\mathrm{K}$ samples for significant difference; the hypothesis is therefore $H_{o}: \mu_{1}=\mu_{2}=\cdots=\mu_{k}$ vs. $H_{1}$ : At least two populations means differ.

\subsection{Model Diagnostics}

First the equality of the covariance matrices was tested with Box M test of equality of covariance matrices of the groups (sex, Age and department) under study. The hypothesis for testing the equality of covariance matrices was stated as: $\mathrm{H}_{0}: \Sigma_{1}=\Sigma_{2} \mathrm{Vrs} \mathrm{H}_{1}$ : At least one Sigma's is different. From table 1, we observed the $p$ values are greater than the significance $(\alpha)$ level of $5 \%$ across the three group variables. Therefore, we fail to reject the null hypothesis of no difference and conclude that, all the covariance matrices are equal across the groups.

Table 1: Test for equality of covariance matrices

\begin{tabular}{llllll}
\hline Group Variables & Box's M & F - value & df1 & df2 & P -value \\
\hline Sex & 2.972 & 0.469 & 6 & 24373.132 & 0.833 \\
Age & 21.109 & 1.515 & 12 & 1414.174 & 0.112 \\
Department & 12.969 & 0.998 & 12 & 1574.745 & 0.448 \\
\hline \hline
\end{tabular}

Figure 1 present the diagnostic plots of the residuals of the performance Indicators. Clearly, the quantile plots indicate that the residuals are normally distributed. Also, the plot of the residuals and the predicted 
values revealed that the residuals are random. Thus the residuals of the performance Indicators are well behaved indicating that the residuals are independent. Further, a diagnostic test (Table 2) of normality with DoornikHansen test and Jarque-Bera test both gave a $P$-value greater than $5 \%$ level of significance, indicating that all the indicator variables are approximately normal.

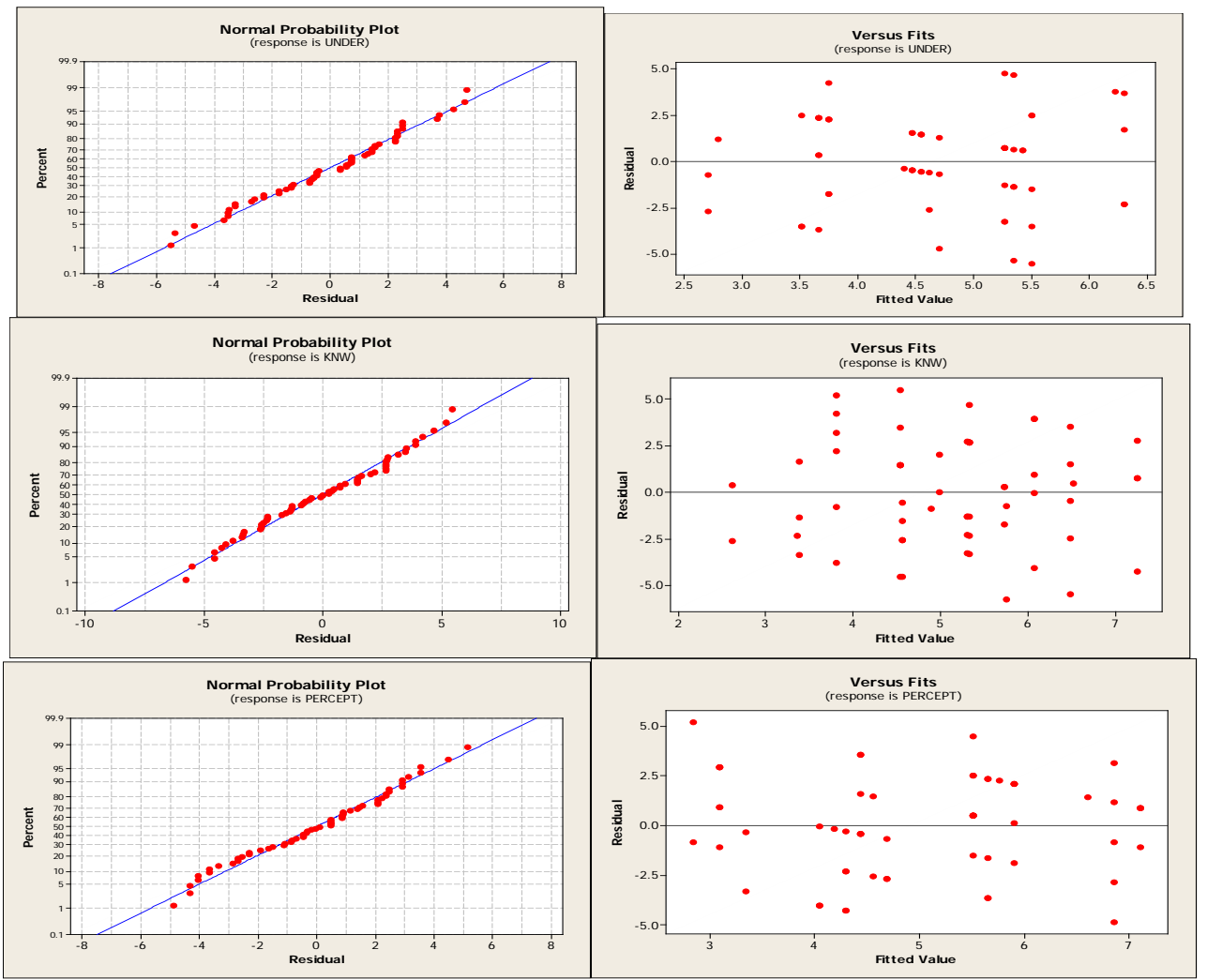

Figure 1: Diagnostics plots of performance Indicators

Table 2: Normality Test

\begin{tabular}{lllllll}
\hline & $\begin{array}{l}\text { Doornik-Hansen } \\
\text { Test }\end{array}$ & & & Jarque-Bera Test & \\
\hline Indicators & Statistics & df & P-value & Statistics & df & P-value \\
\hline Understanding & 4.3438 & 60 & 0.1139 & 3.0182 & 60 & 0.2211 \\
Knowledge & 0.0372 & 60 & 0.9816 & 0.2009 & 60 & 0.9045 \\
Perception & 0.9923 & 60 & 0.1359 & 2.7429 & 60 & 0.2537 \\
\hline \hline
\end{tabular}

\section{Results and Discussions}

The average performance and standard deviations of males and females in mathematics measurement for a sample of 60 are presented in table 3. The results from the table indicated that, male students perform better on the average for all the mathematics performance indicators. However, that at this stage, the preliminary results from the study indicated a 
close disparity in the mean performance of males and female students across all the performance indicators. The skewness and kurtosis values of the performance indicators are also shown in Table 3, which indicates that, their distributions are very close to normality since they all have smaller values of these statistics.

Table 3: Summary Measures of Performance Indicators

\begin{tabular}{lllllll}
\hline & Mean & \multicolumn{5}{c}{ Std. dev } \\
\hline Variable & Male & Female & Male & Female & Skewness & Kurtosis \\
\hline Understanding & 4.87 & 4.47 & 2.662 & 2.609 & -0.043 & -1.188 \\
Knowledge & 5.7 & 4.57 & 2.961 & 3.115 & -0.101 & -1.070 \\
Perception & 5.73 & 4.3 & 2.119 & 2.842 & -0.210 & -1.943 \\
\hline \hline
\end{tabular}

In order to investigate sex differences in mathematics, a MANOVA procedure was used. The results from univariate analysis of variance (ANOVA) for understanding, knowledge were both not significant (Table 4) at the $5 \%$ significance level. This indicates that there were no sex differences among student's mathematical understanding and knowledge. This result is consistent with Ato and Adelaide, (2015) which identified performance assessment and performance-driven instruction improved students' problemsolving abilities and showed no bias among gender. The results further revealed that, there exist statistical significant differences (Table 4) in perception of mathematics among male am female students at $5 \%$ level of significance. A study in Kenya which employed a likert scale to measure students' attitude towards mathematics also reported that students had positive attitude (perception) towards mathematics.

Table 4: Univariate Results

\begin{tabular}{llllll}
\hline & & & Mean & & \\
Source & DF & Type III SS & squares & F-value & Pr $>$ F \\
\hline Understanding (Sex) & 1 & 2.4 & 2.4 & 0.35 & 0.5590 \\
Knowledge (Sex) & 1 & 19.2667 & 19.2667 & 0.209 & 0.1540 \\
Perception (Sex) & 1 & 30.8167 & 30.8167 & 4.38 & $0.0408^{*}$ \\
\hline Understanding (Age) & 2 & 45.0747 & 22.5373 & 3.57 & $0.0347^{*}$ \\
Knowledge (Age) & 2 & 72.2674 & 36.1337 & 4.27 & $0.0188^{*}$ \\
Perception (Age) & 2 & 14.1169 & 7.0584 & 0.95 & 0.3939 \\
\hline Understanding (Department) & 2 & 29.7333 & 14.8667 & 2.26 & 0.1400 \\
Knowledge (Department) & 2 & 93.2333 & 46.6167 & 5.76 & $0.0053^{*}$ \\
Perception (Department) & 2 & 97.4333 & 48.716 & 8.13 & $0.0008^{*}$ \\
\hline \hline
\end{tabular}

$*=$ Significant at $5 \%$

MANOVA calculates four multivariate test statistics. All four are based on the characteristic roots; these are the eigenvalues of the product of the sum-of-squares matrix of the model and the sum-of-squares matrix of the error. The null hypothesis for each of these tests is the same. The result of the multivariate tests in table 5 further affirms that sex has no effect on any 
of the dependent variables (understanding, knowledge and perception of mathematics). The results of no difference in performance by male and female students in terms of mathematics performance contradicted the findings of Ross, Scott, \& Bruce, 2012 (cited by Foy 2013) where males students were found to perform higher base on their knowledge in mathematics, understanding in mathematics and perception in mathematics than females on measures of mathematical performance, especially on more difficult items, but supported the view of Chinwuba \& Osamuyimen ( 2011), that there was no difference in academic performance between male and female Senior High School students.

Table 5: Multivariate Test Results for Sex

\begin{tabular}{llllll}
\hline Statistic & Value & F - Value & Num DF & Den DF & Pr $>$ F \\
\hline Wilk's Lambda & 0.9284 & 1.44 & 3 & 56 & 0.2409 \\
Pillai's Trace & 0.0716 & 1.44 & 3 & 56 & 0.2409 \\
Hotelling-Lawley Trace & 0.7714 & 1.44 & 3 & 56 & 0.2409 \\
Roy's Greatest Root & 0.07714 & 1.44 & 3 & 56 & 0.2409 \\
\hline \hline
\end{tabular}

Num DF = Numerator Degree of Freedom, Den DF = Denominator Degree of Freedom

Furthermore, to test whether there were differences in students mathematics performance across age, students was categorized into three different categories comprising; less than 15 years, 15 - 20 years and $21-25$ years and the MANOVA procedure was used again. The results revealed that significant (Table 4) difference existed in understanding and knowledge in mathematics respectively, while no significant difference (table 4) in perception of mathematics. More so, the multivariate results (Table 6) indicate however that, there is no significant difference among students age in mathematics performance. But Benbow and Stanley, 1980 (cited by Foy 2013) found that boys had consistently better in understanding, knowledge acquisition and perception (scores) on the mathematical portion than girls, even when their content was almost identical.

Table 6: Multivariate Test Results for Age

\begin{tabular}{llllll}
\hline Statistic & Value & F - Value & Num DF & Den DF & Pr $>$ F \\
\hline Wilk's Lambda & 0.8204 & 1.91 & 6 & 110 & 0.0859 \\
Pillai's Trace & 0.1797 & 1.84 & 6 & 112 & 0.0970 \\
Hotelling-Lawley Trace & 0.2187 & 1.99 & 6 & 71.583 & 0.0787 \\
Roy's Greatest Root & 0.2178 & 4.04 & 3 & 56 & $0.0110^{*}$ \\
\hline \hline
\end{tabular}

Num DF = Numerator Degree of Freedom, Den DF = Denominator Degree of Freedom

In addition, to investigate whether the course students study (department) has effect on their mathematics performance, students were sorted in to three departments in the school (Science, Arts and Business) and once again the MANOVA procedure was used. Individual ANOVA results revealed that there were significant differences (Table 4) in students' 
mathematical knowledge and perception at 5\% level, but no difference exist in students' mathematical understanding across course of study (department). Results (Table 6) from the MANOVA procedure revealed that, there is statistical significant difference in mathematical performance of student across department at 5\% level of significance since the p values of all the test statistics are less than 5\%.this result support the general belief that science students have a better understanding, knowledge and good perception of mathematics.

Table 6: Multivariate Test Results for Department

\begin{tabular}{llllll}
\hline Statistic & Value & F - Value & Num DF & Den DF & Pr > F \\
\hline Wilk's Lambda & 0.7002 & 3.58 & 6 & 110 & $0.0028^{*}$ \\
Pillai's Trace & 0.3161 & 3.5 & 6 & 112 & $0.0033^{*}$ \\
Hotelling-Lawley Trace & 0.4049 & 3.68 & 6 & 71.583 & $0.0031^{*}$ \\
Roy's Greatest Root & 0.3356 & 6.27 & 3 & 56 & $0.0010^{*}$ \\
\hline \hline
\end{tabular}

Num DF = Numerator Degree of Freedom, Den DF = Denominator Degree of Freedom $*=$ Significant at $5 \%$

\section{Conclusion and Recommendations}

In this study, the effects of performance indicators of mathematics (understanding, knowledge and perception) of students in the Nelerigu Senior High School in the East Mampurisi District of the Northern Region of Ghana were investigated. The results revealed that students performance in mathematics do not differ across sex (gender) and age group. The study revealed that there was no sex difference among student's mathematical understanding and knowledge while statistical significant differences exist in perception of mathematics among male am female students. However, the studies revealed that significant difference existed in students understanding and knowledge in mathematics, while no significant difference in perception of mathematics among students age.

The study further revealed that that there were significant difference in students mathematical knowledge and perception, but no difference exist in students mathematical understanding across course of study (department). Overall, the result revealed that there is statistical significant difference in mathematical performance of student across course of study (department) in Senior High Schools in Ghana. The study therefore recommended that, the Ministry of Education, school managements and other stakeholders such as Non Governmental Organizations should sensitize students to discard beliefs and practices that prohibit effective participation of female students which result to poor performance in mathematics. Mathematics teachers should review their teaching instructions and engaged females, especially non science students and give them equal opportunities in the classroom so as to build their confidence in the subject. 


\section{References}

1. Ajai, J.T. \& Imoko, I.I. (2015). Gender differences in mathematics achievement and retention scores: A case of problem-based learning method. International Journal of Research in Education and Science (IJRES), 1(1), 45- 50.

2. Ato K. A and Adelaide K. O. (2015). Gender Differences and Mathematics Achievement of Senior High School Students: A Case of Ghana National College. Journal of Education and Practice. Vol.6, No.33.

3. Benbow C. P., \& Stanley J. C. (1980). Sex differences in mathematical ability: Fact or artifact? Science, 210, 1262-1264.

4. Benbow, C. P., \& Stanley, J. C. (1983). Sex differences in mathematical reasoning ability: More facts. Science, 222, 1029-1031.

5. Egodawatte G. (2011) Secondary School Students’ Misconceptions In Algebra. Retrieved

from https://tspace.library.utoronto.ca/bitstream/1807/29712/1/Egodawatte ArachchigeDon_Gunawardena_201106_.pdf.pdf( accessed from $28^{\text {th }}$ April, 2016 9:10 pm ).

6. Foy C. (2013). Gender Differences in Mathematics. EMAT 7050. University of Georgia.

7. Ghana Population and Housing Census (2010). District Analytical Report for the East Mampurisi District. Ghana Statistical Service retrieved

from http://libraries.sta.uwi.edu/journals/ojs/index.php/cts/article/viewFile/ $10 / 7$.

8. Johnson R .A. and Wichern D. W. (2007) Applied multivariate statistical analysis, 6th edn. Prentice Hall, Upper Saddle River

9. Ministry of Education (1986). Report of the Education Commission on Basic Education. Accra: Ghana Publishing Cooperation. http://www.newafrica.com/ethiopia/ministry/education (Accessed: April 19, 2013).

10. O’Connor-Petruso S., Schiering M., Hayes B. and Serrano B. (2004). Pedagogical and Parental Influences in Mathematics Achievement by Gender among Selected European Countries from the TIMSS-R Study, in Proceedings of the IRC-2004 TIMSS Vol. II (ed.) C. Papanastasiou,

11. (Cyprus University, Nicosia, 2004) 69-84.

12. Zachariah K. M., Komen K., George M. M. and George R. N. (2012). Factors Contributing to Students' Poor Performance in Mathematics at Kenya Certificate of Secondary Education in Kenya: A Case of Baringo County, Kenya. American International Journal of Contemporary Research. Vol. 2 No. 6. 